\title{
Study on Mine Ecological Restoration Deposit System Based on Evolutionary Game
}

\author{
Feifei $\mathrm{CaO}^{1,2, \mathrm{a}{ }^{*}}$,Guangcheng Wang ${ }^{2, \mathrm{~b}}$ \\ ${ }^{1}$ School of Management Science and Engineering, Shandong Normal University, Jinan, \\ 250014,China \\ ${ }^{2}$ Schoolof Management Science and Engineering,Shandong Institute of Business and \\ Technology, Yantai ,264005,China \\ a*scaofei@126.com, bocwang658@sina.cn
}

\begin{abstract}
Keywords: Mine environment restoration; Deposit system; Evolutionary game theory; Simulation Abstract. In 2006,our government further deepened the reform of coal resources paid use system, and gradually established coal mine environment and ecological restoration responsibility mechanisms, implementing mine ecological restoration deposit system. However,there is risk in the process of the deposit system implementation, some enterprises escaping ecological restoration through camouflage. There are more likely to appear in collision between mining enterprises and government, sacrificing environment to embezzlement deposit. Based on game theory, this paper studies the relationship between coal mining enterprises and local government in the process of the deposit system implementation. By constructing and analyzing game model, the conclusion reaches as following:when incentive subsidy by higher authorities is greater than local government regulatory costs, the higher the actual probability of regulatory success, the easier the system tends to local government regulatory, compliance ecological restoration of coal mining enterprises; when the actual probability of regulatory success is low, the system can not evolve into socially desired optimal state by increasing penalties. The actual probability of regulatory success and incentive subsidy of higher authorities have a key role in the implementation of mining ecological restoration deposit system.
\end{abstract}

\section{Introduction}

Coal mining promotes the rapid growth of mining economy and society, but also increases burden of environment,causing serious environmental problems, such as a large areas of land subsidence and pollution, the destruction of vegetation, pollution of groundwater systems, which seriously affect the daily life of the mining area residents. Once the coal resources exhaustion, destruction of the ecological environment lack of reconstruction, economic and social development would be in trouble. As the long-term interests, achieving the sustainable development of the mining area, the implementation of mine ecological restoration deposit system is imperative.

The mine ecological restoration deposit system made it clear in 2006, by Treasury, Land Resources, Environmental Protection Administration jointly issued the "guidance on the gradual establishment of mining environmental management and ecological restoration accountability mechanisms," which put forward specific requirements to the use and regulatory of deposit .Based on the use of space, the new mine design life or the remaining service life of the old mines, environmental remediation costs and other factors to determine a certain proportion of sales revenue as ecological restoration deposit, and included in the cost.According to the principle "all business, government regulation, earmarking", the deposit would be returned to the mining companies after completion the mine ecological restoration and acceptance by the relevant departments. ${ }^{[1]}$ If the mining companies failed to complete ecological restoration, and founded by acceptance department, the deposit would be confiscated to restore the mine ecological environment. The implementation of the deposit system internalized the cost of environmental pollution by the exploitation of mineral resources, and supported a legal constraint to environmental governance practices, which had great significance for healthy development of mining ecosystem. 
The universal implementation ecological restoration deposit in china plays an important role in the mine environmental promotion, but also facing some problems.There are some moral risk, particularly at the probability of successful regulation is low, coal mining enterprises can obtained ecological restoration deposit by camouflage rather than completing ecological restoration. The local governments even in collude with the mining companies to embezzle deposit, ignoring environmental destruction. Therefore, we establish evolutionary game model based on ecological restoration of coal mining enterprises and local government regulators to analysis the main factors affecting the environmental restoration of the smooth implementation of the deposit system, exploring the optimal conditions for a stable equilibrium strategy to achieve socially expectations.

\section{Evolutionary game model}

In conventional game theory, the strength of the Nash equilibrium concept rests upon three imperative assumptions: rational behavior of all the agents;complete sharing of empirical information;all the agents have common knowledge of these assumptions. The rigidity of these assumptions leaves Nash equilibrium vulnerable to criticism because we can easily imagine situations where any or all of these assumptions can not realistically hold. We use evolutionary game theory(EGT) that is developed from the strong requirements of irrationality, knowledge of the game and information sharing .

It is assumed that there are two types of players in the game: local government environmental authorities and coal mining enterprises who are the agents of mine ecological restoration deposit system and take part in the game by playing different strategies.

We consider two pure strategies for each of the player of the game model i.e. local government environmental authorities and coal mining enterprises. The choice of which strategy depends on comparison between its expected pay-off and average pay-off.

The coal mining enterprises have two pure strategies, $\mathrm{P}_{1}$ and $\mathrm{P}_{2}$ i.e. ecological restoration compliance or no-compliance. The local government environmental authorities have two pure strategies $\mathrm{G}_{1}$ and $\mathrm{G}_{2}$ i.e.regulation or no-regulation.

The payoffs pertaining to various combinations of pure strategies that the the local government environmental authorities and the coal mining enterprises may play are presented in Table 1 .

Table1 Game model encompassing the strategies of government and enterprises

\begin{tabular}{|c|c|c|c|}
\hline \multicolumn{3}{|c|}{ Local governments } \\
\hline \multirow{3}{*}{$\begin{array}{c}\text { Mining } \\
\text { enterprises }\end{array}$} & compliance $\left(\mathrm{x}_{1}\right)$ & regulation $\left(\mathrm{x}_{2}\right)$ & no-regulation $\left(1-\mathrm{x}_{2}\right)$ \\
\cline { 3 - 4 } & & $\mathrm{R}-\mathrm{C}+\mathrm{T}+\mathrm{W}$ & $\mathrm{R}-\mathrm{C}+\mathrm{T}$ \\
& & $-\mathrm{S}-\mathrm{W}+\mathrm{Q}$ & 0 \\
& & & \\
& No-compliance $\left(1-\mathrm{x}_{1}\right)$ & $\mathrm{R}-\mathrm{H}-\theta \mathrm{F}+(1-\theta)(\mathrm{T}+\mathrm{W})$ & $\mathrm{R}-\mathrm{H}+\mathrm{T}$ \\
& & $-\mathrm{S}+\theta$ F- $(1-\theta)(\mathrm{T}+\mathrm{W})$ & $-\mathrm{T}$ \\
\hline
\end{tabular}

Note: Table notes

$\mathrm{R}$ : represents the revenue of coal mining by enterprises;

$\mathrm{C}$ : represents the costs spending on ecological restoration compliance;

$\mathrm{T}$ : represents the ecological restoration deposit;

$\mathrm{S}$ : represents the costs of government regulation;

$\mathrm{H}$ : represents the camouflage costs spending on ecological restoration no-compliance;

F: represents the penalties when government discovered the ecological restoration nocompliance;

$\mathrm{W}$ : represents the incentives by government; 
Q:represents the incentives subsidy of higher government when government regulation and the ecological restoration compliance;

$\theta$ : represents the probability of successful regulation

$\mathrm{x}_{1}$ :represents the proportion of enterprises which ecological restoration is compliance, and the rest $\left(1-\mathrm{x}_{1}\right)$ prefer to no-compliance.

$\mathrm{x}_{2}$ : represents the proportion of government who supervise the ecological restoration, and the rest $\left(1-\mathrm{x}_{2}\right)$ prefer to no-regulation.

Let denote ' $\mathrm{x}_{1}(\mathrm{t})$ ' as the proportion of enterprise adopting $\mathrm{P}_{1}$ at the instant of time $t, 0 \leq \mathrm{x}_{1}(\mathrm{t}) \leq 1$. Analogously, let ' $\mathrm{x}_{2}(\mathrm{t})$ ' denote the proportion of government adopting $\mathrm{G}_{1}$ at the instant of time $t$, $0 \leq \mathrm{x}_{2}(\mathrm{t}) \leq 1$.

Let , $\mathrm{EP}_{\mathrm{i}}\left(\mathrm{x}_{1}, \mathrm{x}_{2}\right)$ the expected pay-off of the enterprise when adhering to strategy $\mathrm{P}_{\mathrm{i}}$ against all possible government strategies, $\mathrm{i}=1,2 . \mathrm{EG}_{\mathrm{j}}\left(\mathrm{x}_{1}, \mathrm{x}_{2}\right)$ the expected pay-off of the government when adhering to strategy $\mathrm{G}_{\mathrm{j}}$ against all possible enterprise strategies, $\mathrm{j}=1,2$.

$$
\begin{aligned}
E P_{1} & =x_{2}(R-C+T+W)+\left(1-x_{2}\right)(R-C+T) \\
& =R-C+T+x_{2} W \\
E P_{2} & =x_{2}(R-H-\theta F+(1-\theta)(T+W))+\left(1-x_{2}\right)(R-H+T) \\
& =R-H+T+x_{2} W-x_{2}(F \theta+T \theta+W \theta) \\
E G_{1} & =x_{1}(-S-W+Q)+\left(1-x_{1}\right)(-S+\theta F-(1-\theta)(T+W)) \\
& =-S-T-W+x_{1} Q+x_{1} T+\theta T+\theta W+\theta F-x_{1}(\theta T+\theta F+\theta W) \\
E G_{2} & =x_{1} 0+\left(1-x_{1}\right)(-T) \\
& =-\left(1-x_{1}\right) T
\end{aligned}
$$

We define $\overline{E P}$ and $\overline{E G}$ as the average pay-off of the players and express them as:

$$
\begin{aligned}
& \overline{E P}=E P_{1} * x_{1}+E P_{2}\left(1-x_{2}\right) \\
& \overline{E G}=E G_{1} * x_{2}+E G_{2}\left(1-x_{2}\right)
\end{aligned}
$$

The process of adopting strategies is modeled by the replicator dynamics,according to which the strategies whose expected payoffs are greater than the average pay-off spread within the population at the expense of the others:

$$
\begin{aligned}
& \dot{x_{1}}=x_{1} *\left(E P_{1}-\overline{E P}\right) \\
& \dot{x_{2}}=x_{2} *\left(E G_{1}-\overline{E G}\right)
\end{aligned}
$$

We get the replicator dynamic equation of enterprises:

$$
\begin{aligned}
& \dot{x}_{1}=\frac{d x_{1}}{d t}=x_{1}\left(1-x_{1}\right)\left(H-C+x_{2} F \theta+x_{2} T \theta+x_{2} W \theta\right) \\
& \dot{x}_{2}=\frac{d x_{2}}{d t}=x_{2}\left(1-x_{2}\right)\left(\theta T+\theta F+\theta W-S-W-x_{1}(-Q+\theta T+\theta F+\theta W)\right)
\end{aligned}
$$

Numerical strategic values are arrived at by equating the equations to zero. The solution pool now contains a set of strategy pairs that meet the equilibrium criteria.We use the standard Jacobian Matrix(J) for evaluating the asymptotic stability of an equilibrium strategy pair and obtain the evolutionary stable values ${ }^{[2]}$.

$$
J=\left[\begin{array}{ll}
\frac{\partial \dot{x}_{1}}{\partial x_{1}} & \frac{\partial \dot{x}_{1}}{\partial x_{2}} \\
\frac{\partial \dot{x}_{2}}{\partial x_{1}} & \frac{\partial \dot{x}_{2}}{\partial x_{2}}
\end{array}\right]
$$

Any solution pair that satisfies the requirement which 
$\operatorname{det}(\mathrm{J})=\left[\left(\frac{\dot{\partial} x_{1}}{\partial x_{1}}\right) *\left(\frac{\dot{\partial x} x_{2}}{\partial x_{2}}\right)-\left(\frac{\dot{\partial} x_{1}}{\partial x_{2}}\right) *\left(\frac{\dot{\partial} x_{2}}{\partial x_{1}}\right)\right]>0$ and $\operatorname{tr}(\mathrm{J})=\left(\frac{\dot{\partial} x_{1}}{\partial x_{1}}\right)+\left(\frac{\dot{\partial} x_{2}}{\partial x_{2}}<0\right.$.

The following are discussions about stability of dimensional dynamical systems. Stability

analysis results of these four cases are shown in Table 2.

when $\theta \mathrm{F}+\theta \mathrm{T}+\theta \mathrm{W}-\mathrm{W}<\mathrm{S}<\mathrm{Q}, \mathrm{C}-\mathrm{H}<\theta \mathrm{F}+\theta \mathrm{T}+\theta \mathrm{W},(0,0)$ and $(1,1)$ are evolutionary stable strategy of the dynamic system i.e. That costs on the local government regulation are more than its revenues when finding ecological restoration is no-compliance,but less than environmental benefits, the losses of enterprise ecological restoration no-compliance are more than the cost savings. In this case, $\theta_{\mathrm{f}}$ $<\theta<\theta_{\mathrm{g}}$.

when $\theta \mathrm{F}+\theta \mathrm{T}+\theta \mathrm{W}-\mathrm{W}>\mathrm{S}, \mathrm{C}-\mathrm{H}>\theta \mathrm{F}+\theta \mathrm{T}+\theta \mathrm{W},(0,1)$ is evolutionary stable strategy of the dynamic system i.e. That costs on the local government regulation are less than its revenues when finding ecological restoration is no-compliance the losses of enterprise ecological restoration no-compliance are less than the cost savings.In this case, $\theta<\theta_{\mathrm{f} . .}$

when $\theta \mathrm{F}+\theta \mathrm{T}+\theta \mathrm{W}-\mathrm{W}<\mathrm{S}, \mathrm{C}-\mathrm{H}>\theta \mathrm{F}+\theta \mathrm{T}+\theta \mathrm{W},(0,0)$ is evolutionary stable strategy of the dynamic system i.e. That costs on the local government regulation are more than its revenues when finding ecological restoration is no-compliance, but less than environmental benefits, the losses of enterprise ecological restoration no-compliance are less than the cost savings.In this case, $\theta<\min \left(\theta_{\mathrm{g}}, \theta_{\mathrm{f}}\right)$.

when $\theta \mathrm{F}+\theta \mathrm{T}+\theta \mathrm{W}-\mathrm{W}>\mathrm{S}, \quad \mathrm{C}-\mathrm{H}<\theta \mathrm{F}+\theta \mathrm{T}+\theta \mathrm{W},(1,1)$ is evolutionary stable strategy of the dynamic system i.e. That costs on the local government regulation are less than its revenues when finding ecological restoration is no-compliance, the losses of enterprise ecological restoration no-compliance are more than the cost savings.In this case, $\theta>\max \left(\theta_{\mathrm{g}}, \theta_{\mathrm{f}}\right)$.

Table 2 Results of stability analysis

\begin{tabular}{|c|c|c|c|c|}
\hline equilibrium & Det(J) & $\operatorname{Tr}(\mathrm{J})$ & stability & conditions \\
\hline $\mathrm{x}_{1}=0, \mathrm{x}_{2}=0$ & + & - & ESS & $\begin{array}{c}\theta \mathrm{F}+\theta \mathrm{T}+\theta \mathrm{W}-\mathrm{W}<\mathrm{S}<\mathrm{Q}, \\
\mathrm{C}-\mathrm{H}<\theta \mathrm{F}+\theta \mathrm{T}+\theta \mathrm{W}\end{array}$ \\
\hline $\mathrm{x}_{1}=1, \mathrm{x}_{2}=0$ & + & + & $\begin{array}{c}\text { Unstable } \\
\text { points }\end{array}$ & $\begin{array}{c}--------- \\
\end{array}$ \\
\hline $\mathrm{x}_{1}=0, \mathrm{x}_{2}=1$ & + & - & ESS & $\begin{array}{c}\theta \mathrm{F}+\theta \mathrm{T}+\theta \mathrm{W}-\mathrm{W}>\mathrm{S}, \\
\mathrm{C}-\mathrm{H}>\theta \mathrm{F}+\theta \mathrm{T}+\theta \mathrm{W}\end{array}$ \\
\hline $\mathrm{x}_{1}=1, \mathrm{x}_{2}=1$ & & & & $\mathrm{C}-\mathrm{H}<\theta \mathrm{F}+\theta \mathrm{T}+\theta \mathrm{W}$ \\
\hline $\mathrm{x}_{1}=\mathrm{p}_{0}, \mathrm{x}_{2}=\mathrm{q}_{0}$ & ------- & 0 & Saddle Point & ---------- \\
& & & & \\
\hline
\end{tabular}

\section{Numerical Analysis and Simulation}

In this section, we propose a numerical study to the scenario discussed in the previous section.Numerical assumption for the model discussed are made after literature review and a study of a coal company and the local government.In addition to the variable $\theta$, we get the approximate values of the other parameters(per unit)from the coal enterprises and the local government. 
$\mathrm{R}=20, \mathrm{C}=6, \mathrm{~T}=8, \mathrm{~W}=2, \mathrm{~S}=4, \mathrm{H}=3, \mathrm{Q}=10, \mathrm{~F}=5$, it can be obtained by calculation: $\theta_{\mathrm{g}}=0.4, \theta_{\mathrm{f}}$ $=0.2$

The dynamic evolution process based on variable $\boldsymbol{\theta}$. when $\theta=0.3, \theta_{\mathrm{f}}<\theta<\theta_{\mathrm{g}} \mathrm{p}_{0} \approx 0.27, \mathrm{q}_{0} \approx$ 0.667 ,assuming that the initial proportion of the system are $\mathrm{x}_{1}=0.2, \mathrm{x}_{2}=0.4$ and $\mathrm{x}_{1}=0.3, \mathrm{x}_{2}=0.7$ respectively. The finial results of the system are associated with the initial state are shown in Fig.1. Initially, if $\mathrm{p}<\mathrm{p}_{0}, \mathrm{q}<\mathrm{q}_{0}$, the probability of regulation successfully predicted by government is high, there will be more proportion of regulation, however, the probability of regulation successfully predicted by enterprises is low,most coal enterprises choose not to complete ecological restoration. with the game conduct, the government realize that the regulation revenues are so low that the proportion of regulation gradually decreases, enterprises are more inclined to ecological restoration no-compliance, the system eventually evolved into ecological restoration no-compliance, no-regulation. Initially, if $\mathrm{p}>\mathrm{p} 0, \mathrm{q}>\mathrm{q} 0$, the local government has a strong environmental awareness, the proportion of regulation is high, as the game progresses, coal mining enterprises recognize the governance regulation efforts, there will be a higher proportion of ecological restoration compliance. The system eventually evolves into ecological restoration compliance, regulation.
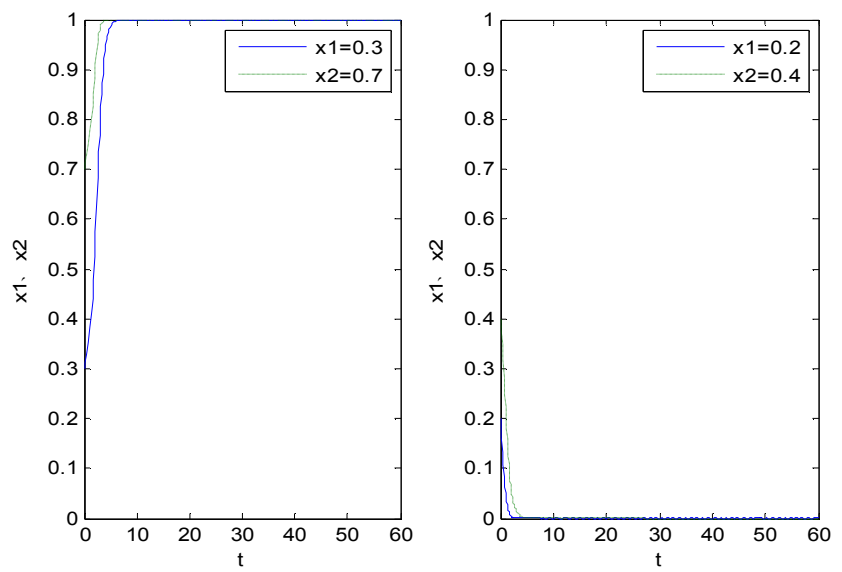

Fig. 1 System evolution in different initial state for fixed $\theta=0.3$

when $\theta=0.1, \theta<\theta_{\mathrm{g}}, \theta<\theta_{\mathrm{f}}, \mathrm{p}_{0} \approx 0.27, \mathrm{q}_{0} \approx 0.667$, the final results of the system evolution are shown in Fig.2(a).No matter what the initial state, the system eventually evolves into ecological restoration no-compliance, no-regulation. In the absence of constraint mechanism , this situation often happens, especially for the high ecological restoration costs, the high costs of government regulation.In the implementation of ecological restoration deposit system, there will be a moral hazard that mining companies and government regulators embezzlement deposit, resulting in abuse of coal resources and further environmental degradation.

when $\theta=0.6, \theta>\theta_{\mathrm{g}}, \theta>\theta_{\mathrm{f}}, \mathrm{p}_{0} \approx 0.27, \mathrm{q}_{0} \approx 0.667$, the final results of the system evolution are shown in Fig.2(b). No matter what the initial state, the system eventually evolved into ecological restoration compliance, regulation, which are social desirable results. 


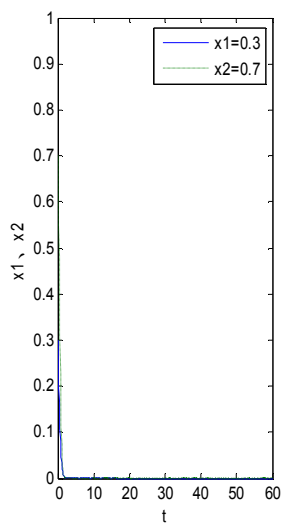

(a)
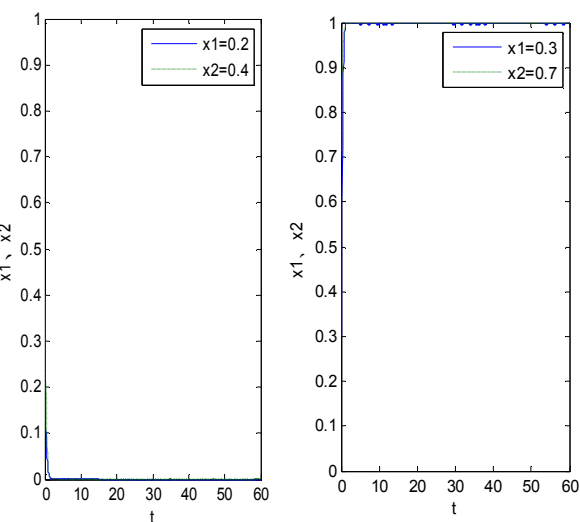

(b)

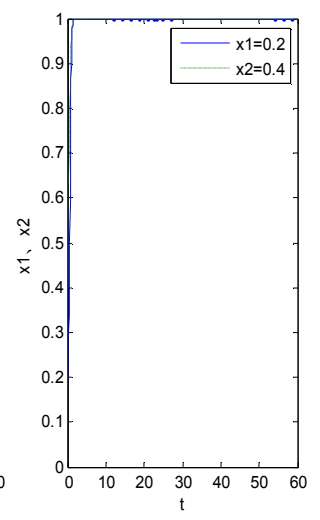

Fig. 2 System evolution in different initial state for fixed $\theta=0.1$ and $\theta=0.6$

The Fig. 1,Fig.2 show that the higher probability of successful regulation,which is more than $\theta_{\mathrm{g}}$ and $\theta_{\mathrm{f}}$, the better results of system evolution. To reached a high probability probability of regulation successfully, on one hand,the government should establish a unified leadership group for the ecological restoration governance to avoid inefficiencies caused by cross-enforcement departments; on the other hand, the government should ameliorate performance evaluation mechanism, not only focusing on economic indicators but also increasing the weight of ecological indicators, focusing on assessing ecological restoration tenure status, and improve the enthusiasm of local governments on implement of ecological restoration deposit system.

The dynamic evolution process based on parameter $\mathbf{H}$.As we fixed variable $\theta=0.3$, increasing the value of $\mathrm{H}, \mathrm{H}=5$, other parameters fixed, the impact on the evolution of the system is shown in Fig.3. No matter what the initial state,the system eventually evolves into ecological restoration compliance,regulation. Hence, government should strengthen regulation, by increasing the camouflage costs to make the system a good evolution result .
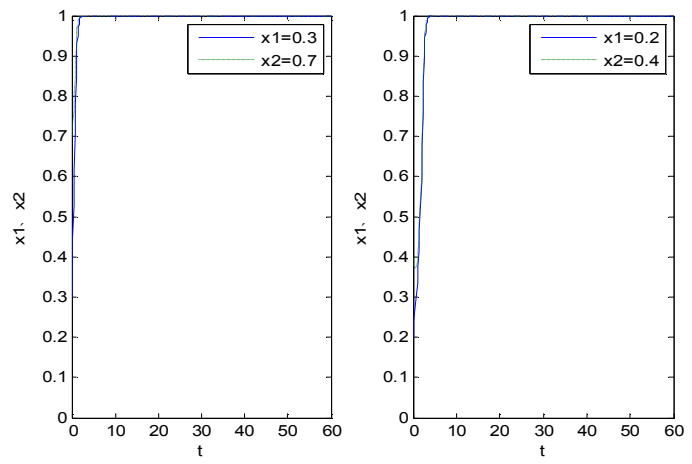

Fig. 3 Effect of $\mathrm{H}$ on system evolution for fixed $\theta=0.3, \mathrm{H}=5$

From Fig.3,we can know that high $\mathrm{H}$ will lead to coal mining enterprises completing ecological restoration. The camouflage reason is the high costs of ecological restoration or the unreasonable deposit system. Therefore, the local government can make full use of tax relief, financial subsidies and other policy instruments, providing technical support for technological innovation to reduce the costs of ecological restoration.At the same time, the deposit system should establish a scientific system of budget.the amount of deposit should not contain only the cost of land reclamation ,but should fully consider the cost of repair and treatment of mine the entire complex ecosystem, and the actual capacity of the coal enterprises. The credit system of mine ecological restoration deposit is essential, allowing to take a different payment methods and payment proportion depending on the effectiveness of past environmental remediation performance and social credibility level.Such as allowing coal 
mining enterprises to apply for a bank guarantee and paying a guarantee fee according to reference implementation program of Australia ${ }^{[3]}$.

The dynamic evolution process based on parameter $\mathbf{S}$. As we fixed variable $\theta=0.3$, reducing the value of $S, S=2$, other parameters fixed, the impact on the evolution of the system is shown in Fig 4.No matter what the initial state, the system eventually evolved into ecological restoration compliance,regulation. The government should improve the level of regulation, reduce regulation costs, allowing the system to a good situation .
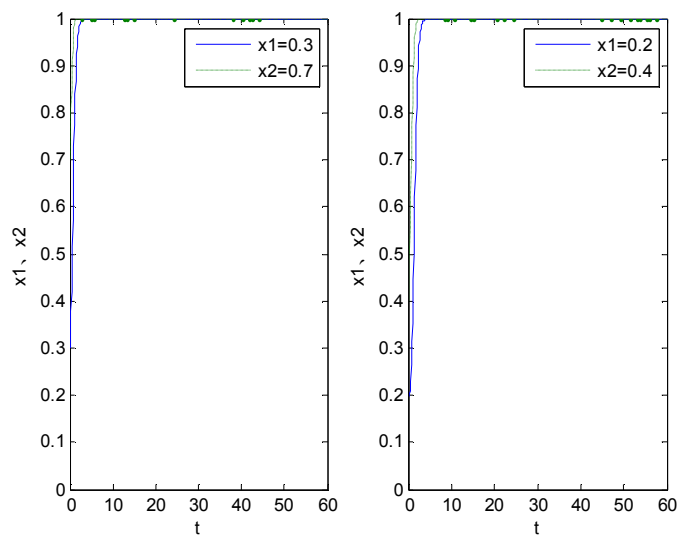

Fig.4 Effect of $\mathrm{S}$ on system evolution for fixed $\theta=0.3, \mathrm{~S}=2$

From Fig.4,we can know that low $\mathrm{S}$ will lead to the local government regulation.Hence,the government should strengthen cooperation with universities and research institutes, improving ecological restoration review mechanism to determine stringent acceptance standards, providing technical support and policy advice for the government .Local government should reduce the cost of mining rights of residents by some financial compensation and in-kind compensation.Enforcement procedures are open and transparent to support convenient channel for the mining residents complaint.

\section{Conclusions}

This paper analysis the relationship between local governments and coal enterprises by evolutionary game. To guarantee the smooth implementation of mine ecological restoration deposit system, the local governments should obtain adequate financial subsidies by higher government,and improve probability of successful regulatory by establishing a comprehensive regulatory system and using advanced technology and the smooth flow of information channels to stimulate the public's enthusiasm.

\section{References}

[1] Treasury(2006) Treasury land Resources Environmental Protection Administration guidance on the gradual establishment of mining environmental management and ecological restoration accountability mechanisms [Z] .(In Chinese)

[2] Maynard Smith J (1982) Evolution and the Theory of Games. Cambridge University Press.

[3] Salam M (2010) Sustainability Metrics for Coal Power Generation in Australia[J]. Process Safety and Environmental Protection, 84:143-149.

[4] Vatn A (2010) An institutional analysis of payments for environmental services [J]. Ecological Economics, 69:1245-1252.

[5] Cheng Qian, ZhangXia (2014) Research of eco-compensation for mineral resources exploitation and the benefit game between parties[J].Mining R\&D,34:127-131.(In Chinese).

[6] Xuegan Zhangg, Maochu Zhong (2011) Game analysis and countermeasures of environmental regulation of government and corporate pollution[J].China population,resources and environment, 21:31-35.(In Chinese) 
[7]Matthew J.Hanon,Timothy J.Foxon, William F.Gale (2013) The co-evolutionary relationship between Energy Service Companies and the UK energy system: Implications for a low-carbon transition[J].Energy Policy,61: 1031-1045.

[8] Shouguang Yan, Weishou Shen, Changxin Zou,etal (2012) Theory and practice of eposit system for restoration and control of mining environment $[\mathrm{J}]$.Environment science \& technology,35:423-427.(In Chinese)

[9] Foxon, T.J. (2011) A co-evolutionary framework for analysing a transition to a sustainable low carbon economy[J]. Ecological Economics, 70, 2258-2267.

[10] Li R, Yu J, Lin J (2013) Evolution of cooperation in spatial Traveler's Dilemma game. PLoS ONE 8: 58597.

[11] Sikhar Barari Gaurav Agarwal,W.J.ZhangBiswajit Mahanty,M.K.Tiwari(2012) A decision framework for the analysis of green supply chain contracts:An evolutionary game approach[J].Expert systems with applications, 39:2965-2976.

[12] Dingwei Wang,Xuwang Liu (2014) Analysis of administrative behaviors for bid evaluation based on evolutionary game[J].Journal of systems engineering,29:773-779.(In Chinese)

[13] Halpern J, Pass R (2012) Iterated regret minimization: A new solution concept.Games and Economic Behavior 74:184-207. 